\title{
Engineered Human Stem Cell Microenvironments
}

\author{
Jacob H. Jordahl ${ }^{1,4}$ • Luis Villa-Diaz ${ }^{6,7}$ • Paul H. Krebsbach ${ }^{4,5,6}$ • Joerg Lahann Ja,3,4,5 $^{1,2}$
}

Published online: 3 February 2016

(C) Springer International Publishing AG 2016

\begin{abstract}
Stem cells have the ability to self-renew and differentiate into specialized cell types, and, in the human body, they reside in specialized microenvironments called "stem cell niches." Although several niches have been described and studied in vivo, their functional replication in vitro is still incomplete. The in vitro culture of pluripotent stem cells may represent one of the most advanced examples in the effort to create an artificial or synthetic stem cell niche. A focus has been placed on the development of human stem cell microenvironments due to their significant clinical implications, in addition to the potential differences between animal and human cells. In this concise review, we describe the advances in human pluripotent stem cell culture and explore the idea that the knowledge gained from this model could be replicated to
\end{abstract}

This article is part of the Topical Collection on Stem Cells and Nanotechnologies

Joerg Lahann

lahann@umich.edu

1 Department of Chemical Engineering, University of Michigan, Ann Arbor, MI 48109, USA

2 Department of Macromolecular Science and Engineering, University of Michigan, Ann Arbor, MI 48109, USA

3 Department of Material Science and Engineering, University of Michigan, Ann Arbor, MI 48109, USA

4 Biointerfaces Institute, University of Michigan, Ann Arbor, MI 48109, USA

5 Department of Biomedical Engineering, University of Michigan, Ann Arbor, MI 48109, USA

6 Department of Biologic and Materials Sciences, University of Michigan, Ann Arbor, MI 48109, USA

7 Department of Biological Sciences, Oakland University, Rochester, MI 48309, USA create synthetic niches for other human stem cell populations, which have proven difficult to maintain in vitro.

Keywords Pluripotent stem cell $\cdot$ Hematopoietic stem cell . Cancer stem cell · Stem cell niche · Engineered surfaces . Polymers

\section{Introduction}

Culturing cells outside of the human body is inherently difficult. Biologists have dedicated decades of research to learning what conditions are most conducive to culturing cells in vitro. This included adaptation of substrates to allow cells to adhere and proliferate for extended periods of time. When polystyrene petri dishes were first implemented for cell culture, they were unable to sustain cell growth due to insufficient cell spreading on the surface $[1,2]$. Surface modification techniques, such as chemical treatments with sulfuric acid [1] or glow discharge [2], were utilized to allow enhanced cell adhesion through the negative surface charge of the polystyrene [3]. These surface modification technologies enabled fundamental studies of how cells interact with their environment and specifically how the substrate affects cell behavior [4]. Surface-modified plastics were among the first man-made microenvironments produced for the sole purpose of culturing cells, and they paved the way to the tissue-culture plastic which is still the gold standard in laboratories around the world today.

The discovery of stem cells brought about a new challenge in cell culture substrate design. Instead of simply growing cells, specific cell properties such as self-renewal and pluripotency or multipotency need to be maintained or controlled. Maintaining these unique stem cell properties during expansion is crucial to create sufficient populations of undifferentiated cells that can then be terminally differentiated [5]. 
While standard tissue culture plastic can be suitable for culturing both primary cells and cell lines, they are not wellsuited for maintaining stemness for prolonged periods of time. Recent trends in development of stem cell substrates have focused on recapitulating the stem cell niche ex vivo in a tissue culture environment. This has been accomplished using strategies such as feeder cells, purified extracellular matrix proteins $(\mathrm{ECM})$, peptide conjugated surfaces or hydrogels, and specialized synthetic polymers, to create a milieu that is conducive to stem cell expansion and maintenance of stem cell properties outside the body (Fig. 1). The development of surfaces capable of preserving the pluripotency of human embryonic stem cells (hESCs) and human-induced pluripotent stem cells (iPSCs) is a major advancement toward defined stem cell microenvironments and may serve as a blueprint for other stem cells with high levels of phenotypic plasticity, such as cancer stem cells or hematopoietic stem cells. This perspective outlines current knowledge in the composition of the stem cell niche and how the niche can be recapitulated in vitro using engineered microenvironments. This is highlighted by examining current trends in the expansion of pluripotent stem cells and relating this progress to the expansion of other stem cells that are difficult to culture. While this review focuses on the development of culture substrates for stem cells, it should be noted that the soluble factors comprising the culture medium also play a significant role in the maintenance of the stem cell phenotype. These aspects are outside of the scope of the perspective, and we refer the interested reader to other reviews that cover this topic in detail [6].

\section{The Stem Cell Niche}

Stem cells have the specific function of producing and replenishing specialized cells during the life of eukaryotic organisms. During early mammalian development, the fertilized egg divides into blastomeres with stem cell properties that give rise to the first two cell lineages: the throphoectoderm cells from the outer blastomeres of the embryo which will form the placenta, and the inner blastomeres will become the inner cell mass (ICM), a population of cells with pluripotent properties [7]. The ICM eventually differentiates into specialized cell types of the three germ layers, namely the ectoderm, mesoderm, and endoderm [7]. In vitro, this pluripotent stage can be maintained over longer periods of time by isolating and expanding the cells comprising the ICM, which are called embryonic stem cells. Throughout life, fetal and adult life stem cells, called somatic stem cells (SSC), are developed and maintained in specialized microenvironments termed stem cell niches. These niches serve as protective environments that provide supportive conditions to maintain stem cell self-renewal and differentiation properties.

The niche is comprised of soluble signaling from cytokines and growth factors, direct interactions with other cells, and the extracellular matrix (ECM). In combination with one another, these components activate signaling pathways involved in the maintenance of the undifferentiated and quiescent states of stem cells. While some signaling pathways and niche elements are commonly expressed among stem cells, there is not a defined pathway present in all of them [8-10].
Fig. 1 Engineered stem cell microenvironments draw inspiration from the in vivo stem cell niche. In an effort to recapitulate functional elements of the stem cell niche, culture substrates have been developed using stromal cells, extracellular matrix proteins, or peptide conjugated polymers. Fully synthetic hydrogels help maintain stem cell pluripotency and selfrenewal by supporting matrix proteins from the medium or secreted by cells. It has also been demonstrated that topology or stiffness are important considerations when creating stem cell microenvironments. In the illustration, stem cells are white, different types of stromal cells are red and green, and ECM proteins are yellow fibrils
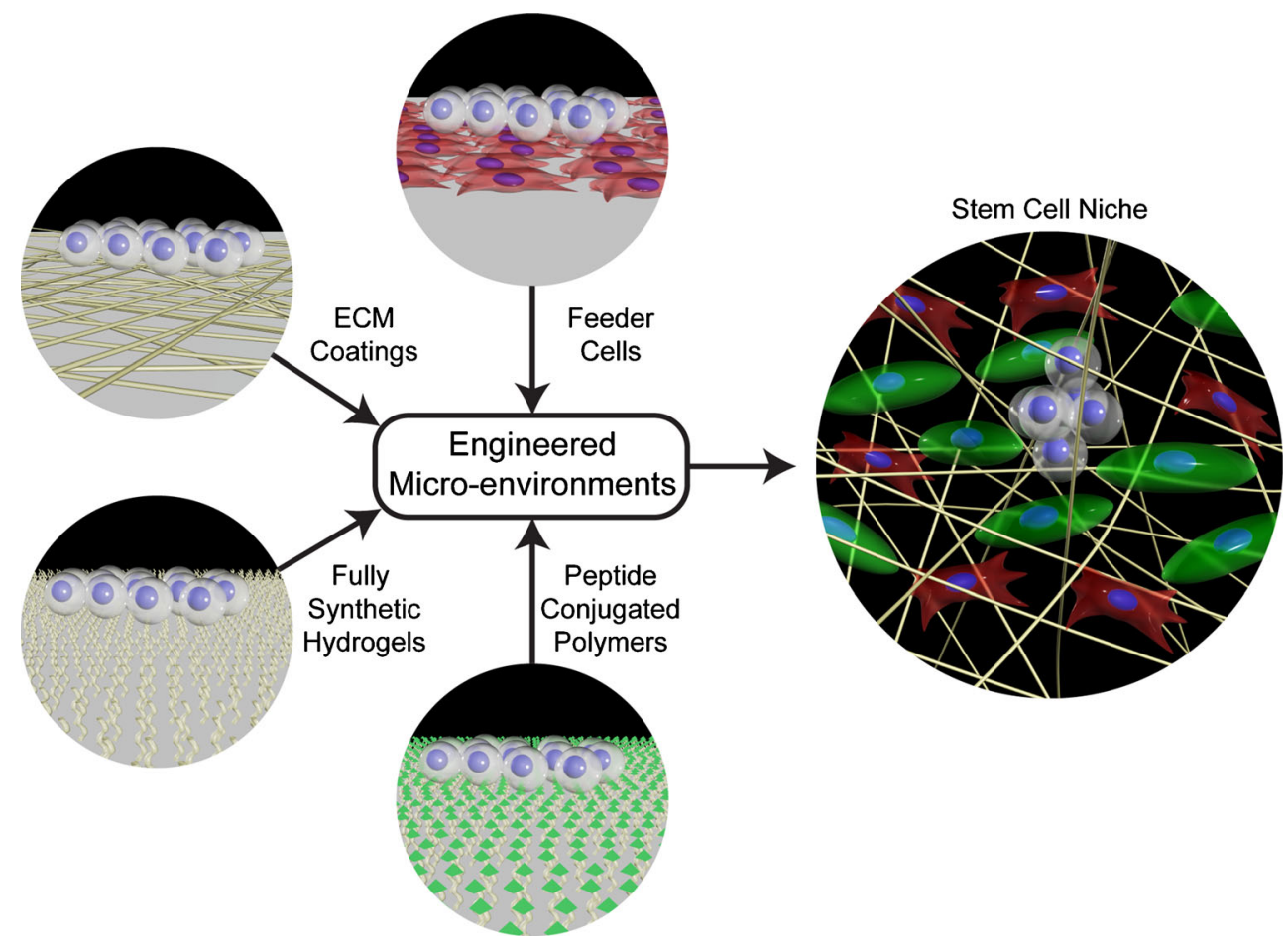
However, literature suggests that a common characteristic between stem cells and their niches can be found in the expression of a specific ECM protein, laminin, and its receptor in the stem cells, integrin $\alpha 6$. The laminin and integrin $\alpha 6$ interaction has been documented as a critical niche component in corneal [11], colonic [12], epithelial [13], hepatic [14], spermatogonial [15], neuronal [16], glioblastoma [17], and embryonic stem cells [18]. Interestingly, laminin is one the first ECM proteins deposited during embryo development, and it is specifically expressed in the blastocyst stage [19], when the ICM is formed and, as explained above, a transient state of pluripotency exists. Human embryonic stem cells, the in vitro counterpart of the pluripotent ICM cells, express integrin $\alpha 6$ [18], and specific isoforms of laminin are able to support their self-renewal and proliferation [20]. Furthermore, although other ECM proteins such as vitronectin [21] and fibronectin [22] can support self-renewal of hESCs, it has recently been shown that hESCs cultured on ECM-coated surfaces remodeled their microenvironment by depositing their own laminin [23•]. Due to the similarities among pluripotent stem cells and several somatic stem cells and their corresponding niches, we propose that the knowledge of the in vitro culture of human pluripotent stem cells could be exploited to bioengineer stem cell niches for somatic stem cells.

\section{Feeder Cells}

The isolation and successful culture of hESCs opened an entirely new outlook on the future of cell and tissue culture. However, this early milestone came with its own set of challenges. While hESCs can adhere to normal tissue-culture plastic, the unique attribute of maintaining self-renewal is lost over time under those conditions. Thus, mitotically inactivated feeder cell layers, a technique derived from earlier work which successfully maintained the pluripotency of mouse embryonic stem cells (mESCs) and mouse embryonal carcinoma cells (mECCs) [24-26], were used to support the culture of hESCs. A study using non-proliferative human oviductal epithelial cells as a feeder layer and human leukemia inhibitory factor (HLIF) to culture the inner cell mass (ICM) of a human blastocyst proved to be the first isolation and culture of human ICM cells, although the cells differentiated toward a fibroblast-like phenotype after two passages [27]. The first hESC lines that could be sustained indefinitely in vitro were cultured on feeder layers composed of mouse embryonic fibroblasts (MEFs) in medium supplemented with FBS [5, 7, 28]. An alternative source of human pluripotent stem cells is provided by human fibroblasts reprogrammed into pluripotent stem cells, termed induced pluripotent stem cells (hiPSCs) [29]. The establishment of hESC and hiPSC lineages provided the platform necessary to investigate (i) what microenvironment is necessary to sustain these cells in a pluripotent state, (ii) how to eliminate components within the microenvironment which are undefined or derived from xenogeneic sources, and (iii) how the physical properties of the microenvironment affect the differentiation and maintenance of these cells.

Similarly, feeder cells and cocultures of stem cells with somatic cells are also used in the expansion and maintenance of human hematopoietic stem cells (HSCs). HSCs are a relatively rare cell type located primarily within the bone marrow, peripheral blood, or umbilical cord blood and are capable of differentiating into all mature blood cells of the human body. HSCs play a critical role in bone marrow transplants used in clinical treatments for hematological disorders such as leukemia, lymphoma, and sickle cell anemia [30]. Ex vivo expansion and maintenance of these rare cells could therefore provide an attractive platform for improving the treatment of several debilitating diseases. Engineering a culture substrate capable of expanding long-term repopulating hematopoietic stem cells began by examining the niche in which they reside. This led to coculture of isolated human HSCs with stromal cells associated with the bone marrow microenvironment and cells which secrete a specific set of cytokines and growth factors which have been attributed to maintaining HSCs [31-35]. Human feeder cells, such as osteoblasts [36] and mesenchymal stem cells [37-39], as well as porcine endothelial cells [40], mouse fetal liver [41], and mouse stromal cells [33], are some examples of the types of feeder cells associated with the expansion of human HSCs in vitro. While the interactions between these supporting cells and HSCs have not been fully characterized, the ability of feeder cells to promote HSC expansion in vitro has shown some degree of success (Table 1). The direct clinical relevance of HSCs to the treatment of blood disorders has led to the extensive use of human feeder cells to provide a microenvironment free from xenogeneic contamination, as opposed to MEFs used in early hESC microenvironments. This has contributed to successful human trials which have demonstrated that ex vivo expansion of HSCs can provide an effective means of improving engraftment efficiency over standard cord blood transplants [76]. While in vitro expansion over short periods of time have demonstrated successes, long-term maintenance of HSCs has yet to be achieved, as it is possible for hESCs. Despite the successes provided by feeder cells to the culture of both hESCs and HSCs, the unknown interactions between the cells in coculture systems contributed to a desire for feeder-free cell culture systems with fully defined media components. Such a culture platform would be used to directly study how the composition of the microenvironment affects stemness. 
Table 1 Representative list of stem cell culture substrates

\begin{tabular}{|c|c|c|c|}
\hline Culture substrate & Cell type & Highlighted results & Reference \\
\hline \multicolumn{4}{|l|}{ Xenogenic feeder cells } \\
\hline MEF feeders & $\begin{array}{l}\text { ICM of blastocyst (derived lines } \\
\mathrm{H} 1, \mathrm{H} 7, \mathrm{H} 9, \mathrm{H} 13, \mathrm{H} 14)\end{array}$ & $\begin{array}{l}\text { Continuously cultured and remained undifferentiated } \\
\text { for over } 8 \text { months }\end{array}$ & [7] \\
\hline MEF feeders & iPSC & $\begin{array}{l}\text { Remained undifferentiated and proliferated for at least } \\
4 \text { months }\end{array}$ & [29] \\
\hline MEF feeders & hESC (derived HES-1, HES-2) & Sustained culture for up to 64 passages & [5] \\
\hline Mouse fetal liver feeders (AFT024) & CD34+ UC-HSPC & $\begin{array}{l}\text { More efficient engraftment in mice than human BM } \\
\text { stromal cell monolayers }\end{array}$ & [41] \\
\hline PMVEC & CD34+ UC-HSPC & $\begin{array}{l}\text { 470-fold increase in CD34+ CD38- population compared } \\
\text { to stroma-free culture }\end{array}$ & {$[40]$} \\
\hline \multicolumn{4}{|l|}{ Human feeder cells } \\
\hline Human Oviductal epithelial feeders & ICM of blastocyst & All cells differentiate after second subculture & [27] \\
\hline Human AFT epithelial feeders & hESC (HES-3, HES-4) & Self-renewal maintained for at least 20 passages & [42] \\
\hline Human FM feeders & hESC (HES-3, HES-4) & Self-renewal maintained for at least 20 passages & [42] \\
\hline Human FS feeders & hESC (HES-3, HES-4) & Self-renewal maintained for at least 20 passages & [42] \\
\hline Human foreskin fibroblast feeders & hESC (derived lines HS181, HS207) & Self-renewal maintained for over 40 weeks & [43] \\
\hline hMSC feeders & CD34+ UC-HSPC & $\sim$ Twofold to 7 -fold increase LTC-IC population & [44] \\
\hline Human osteoblast feeders & $\mathrm{CD} 34+\mathrm{BM}-\mathrm{HSPC}$ & Eightfold increase in $\mathrm{CD} 34+$ population & [36] \\
\hline BM stromal feeders & CD34+ BM-HSPC & $\begin{array}{l}\text { Supported HSPC culture for } 5 \text { weeks and maintained } \\
\text { LTC-IC populations }\end{array}$ & [45] \\
\hline Human prostate CAF & PC3 & Enriched $\mathrm{CD} 44^{\mathrm{hi}} / \mathrm{CD} 24^{\mathrm{lo}} \mathrm{CSC}$ population & [46] \\
\hline Primary colonic human myofibroblasts & Primary human colon carcinoma & CSC differentiation prevented in $2 \mathrm{D}$ culture & [47] \\
\hline BM-hMSC & SUM159, SUM149, MCF-7 & $\begin{array}{l}\text { Threefold increase in cancer stem cell population to } \\
14 \% \text { of total population }\end{array}$ & [48] \\
\hline \multicolumn{4}{|l|}{ ECM coatings/gels } \\
\hline Matrigel & hESC (H1, H7, H9, H14) & Sustained culture for up to 21 passages in defined media & [49] \\
\hline $\begin{array}{l}\text { Combination of laminin, collagen } \\
\text { IV, fibronectin, vitronectin }\end{array}$ & hESC (H1, H9; derived WA15, WA16) & Sustained culture for up to 7 months in defined media & [49] \\
\hline Matrigel & hESC (H1, H7, H9, H14) & $\begin{array}{l}\text { Undifferentiated cells maintained for over } 6 \text { months with } \\
\text { conditioned media }\end{array}$ & [18] \\
\hline Laminin & hESC (H1, H7, H9, H14) & $\begin{array}{l}\text { Undifferentiated cells maintained for at least seven } \\
\text { passages with conditioned media }\end{array}$ & [18] \\
\hline Collagen IV & hESC (H1, H7, H9) & $\begin{array}{l}\text { Some undifferentiated colonies present after six passages } \\
\text { with conditioned media }\end{array}$ & [18] \\
\hline Fibronectin & hESC (H1, H7, H9) & $\begin{array}{l}\text { Some undifferentiated colonies present after six passages } \\
\text { with conditioned media }\end{array}$ & {$[18]$} \\
\hline Vitronectin & hESC (HUES1, HES2, HESC-NL3) & Sustained culture for up to 12 weeks in defined media & [21] \\
\hline Laminin & hESC (HUES1, HES2, HESC-NL3) & hESC growth not supported in defined media & [21] \\
\hline Fibronectin & hESC (HUES1, HES2, HESC-NL3) & hESC growth not supported in defined media & [21] \\
\hline Collagen IV & hESC (HUES1, HES2, HESC-NL3) & hESC growth not supported in defined media & [21] \\
\hline Fibronectin & hESC (I3, I6, H9) & $\begin{array}{l}\text { Sustained undifferentiated } \mathrm{hESCs} \text { for up to } 38 \text { passages } \\
\text { with growth factor addition }\end{array}$ & {$[50]$} \\
\hline Chitosan/alginate scaffold & hESC (BG01V) & Maintained for 21 days in culture in defined media & [51] \\
\hline Gelatin & hESC (I3, I6, H9) & $\begin{array}{l}70 \% \text { more differentiation after } 6 \text { days compared to } \\
\text { fibronectin coating }\end{array}$ & {$[50]$} \\
\hline Laminin-511 & $\begin{array}{l}\text { hESC (HS420, HS207, HS401), } \\
\text { iPSC (BJ\#12, LDS1.4) }\end{array}$ & Self-renewal maintained for over 4 months & [52] \\
\hline Laminin-521 + E-Cadherin & hESC (H1, HS401) & $\begin{array}{l}\text { Efficient derivation and self-renewal of hESCs for over } \\
20 \text { passages with high cloning efficacy }\end{array}$ & [53] \\
\hline $\begin{array}{l}\text { A variety of ECMs and sera } \\
\text { coatings }\end{array}$ & $\begin{array}{l}\text { hESC (HS237, HS293, HS360, } \\
\text { HS401, Regea 06/105, HS237) }\end{array}$ & $\begin{array}{l}\text { All substrates tested were significantly inferrior to Matrigel } \\
\text { in maintaining hESC cultures }\end{array}$ & [54] \\
\hline Vitronectin coated TCPS & $\begin{array}{l}\text { hESC (H9, H14), IPSC (iPS } \\
\text { (IMR-90)-3, iPS(IMR-90)- } \\
\text { 4, iPS(foreskin)-2) }\end{array}$ & Maintained for nine passages & [55] \\
\hline Vitronectin coated UVPS & iPSC & Sustained culture for up to 2 months & [56] \\
\hline Puramatrix ${ }^{\mathrm{TM}}$ Synthetic ECM + hMSC feeders & CD34+ BM-HSPC & Increased LTC-IC population & [57] \\
\hline Fibrin gel $+\mathrm{hMSC}$ feeders & CD34+ UC-HSPC & $\begin{array}{l}\text { More efficient } \mathrm{CD} 34+\text { population enhancement than collagen } \\
\text { I or polymer scaffolds }\end{array}$ & [58] \\
\hline Fibronectin conjugated PET film & CD34+ UC-HSPC & 19-fold increase in CD34+ cells & [59] \\
\hline Fibronectin adsorbed PET fibers & CD34+ UC-HSPC & 2-fold increase in CD34+ cells & [59] \\
\hline Fibronectin conjugated PET fibers & CD34+ UC-HSPC & $\begin{array}{l}\text { 100-fold increase in CD } 34+\text { cells, with } 45 \text {-fold increase in } \\
\text { LTC-IC population }\end{array}$ & [59] \\
\hline Collagen conjugated PET fibers & CD34+ UC-HSPC & $\begin{array}{l}\text { 73-fold increase in CD } 34+\text { cells with } 4 \text {-fold increase in } \\
\text { LTC-IC population }\end{array}$ & [59] \\
\hline
\end{tabular}


Table 1 (continued)

\begin{tabular}{|c|c|c|c|}
\hline Culture substrate & Cell type & Highlighted results & Reference \\
\hline Fibrin gel & A2780, HepG2, primary patient & Formed spheroids indicating enrichment of CSC & {$[60]$} \\
\hline Laminin-coated TCPS & $\begin{array}{l}\text { Primary brain tumors } \\
\quad \text { (derived G144, G166, G179) }\end{array}$ & $\begin{array}{l}\text { Supported cell lines consisting mostly of glioma neural stem } \\
\text { cells }\end{array}$ & [61] \\
\hline Collagen scaffold & MCF-7 & $\begin{array}{l}\text { Increasedangiogenic GF and MMP expression and enhanced } \\
\text { CD44+/CD24- population }\end{array}$ & [62] \\
\hline Fibronectin-coated PDMS & SUM159, MDA-MB-468 & No enrichment of CSCs, not affected by stiffness & [63] \\
\hline BSA-coated PDMS & SUM159, MDA-MB-468 & More than doubled CSC population, not affected by stiffness & [63] \\
\hline Collagen-coated PDMS & SUM159, MDA-MB-468 & No enrichment of CSCs, not affected by stiffness & [63] \\
\hline Laminin-511 coating & $\begin{array}{l}\text { CD44+/CD24- Src-transformed } \\
\text { MCF10A, SUM } 1315\end{array}$ & Increased adhesion and enhanced TAZ gene expression & {$[64 \cdot]$} \\
\hline FBS-coated PCL fibers & MCF-7, T47D, SK-BR-3 & $\begin{array}{l}\text { Threefold increase in proportion of ALDH+ cells, increased } \\
\text { mammosphere formation }\end{array}$ & [65] \\
\hline \multicolumn{4}{|l|}{ Peptide modified surfaces } \\
\hline BSP-PAS & $\mathrm{hESC}(\mathrm{H} 1, \mathrm{H} 7)$ & $\begin{array}{l}\text { Undifferentiated cells maintained for over } 16 \text { passages in } \\
\text { defined media }\end{array}$ & [66] \\
\hline VN-PAS & hESC (H1, H7) & $\begin{array}{l}\text { Undifferentiated cells maintained for over } 16 \text { passages in } \\
\text { defined media }\end{array}$ & [66] \\
\hline sFN-PAS & hESC (H1, H7) & No cell adhesion observed & [66] \\
\hline 1FN-PAS & hESC (H1, H7) & No cell adhesion observed & [66] \\
\hline LM-PAS & $\mathrm{hESC}(\mathrm{H1}, \mathrm{H} 7)$ & No cell adhesion observed & [66] \\
\hline Peptide SAM microarray & hESC (H1, H9) & $\begin{array}{l}\text { Cell adhesion observed with integrin-binding peptides, but } \\
\text { these peptides did not effectively maintain hESCs. Heparin- } \\
\text { binding peptide sequences bound cells and allowed for self- } \\
\text { renewal. }\end{array}$ & [67] \\
\hline GKKQRFRHRNRKG SAM & $\begin{array}{l}\text { hESC (H1, H7, H9, H14), iPSC } \\
\quad(\text { IMR-90, DF19-9 } 7 \text { T) }\end{array}$ & $\begin{array}{l}\text { Heparin binding peptide SAM sustained undifferentiated cells } \\
\text { for } 2-3 \text { months }\end{array}$ & [67] \\
\hline $\begin{array}{l}\text { Amine functional TCPS modified } \\
\text { with CRGD }\end{array}$ & hESC (H9, H14) & $\begin{array}{l}\text { Continuously cultured and remained undifferentiated for at least } \\
\text { ten passages. Superior cell adhesion compared to linear RGDS } \\
\text { sequence. }\end{array}$ & [68] \\
\hline VN-pDA-PS & hESC (H9), iPSC & Sustained culture for over 3 months in defined media & [69] \\
\hline FN-patterned PEGDA & CD34+ UC-HSPC & Enhanced adhesion, no effect on stemness & [70] \\
\hline OPN-patterned PEGDA & CD34+ UC-HSPC & Enhanced adhesion, no effect on stemness & [70] \\
\hline RGD-patterned PEGDA & CD34+ UC-HSPC & Enhanced adhesion, no effect on stemness & [70] \\
\hline $\begin{array}{l}\text { RGDSK-PEG-Acrylate } \\
\text { hydrogel + hMSC feeders }\end{array}$ & CD34+ UC-HSPC & $\begin{array}{l}\text { Increased expansion, CD34+ expression, and early progenitor } \\
\text { cell population }\end{array}$ & [71] \\
\hline RGD-conjugated PEGDA & 4 T1, MCF-7 & Decreased CD $44^{\mathrm{hi}} / \mathrm{CD} 24^{\text {lo }}$ subpopulation of breast cancer cells & [72] \\
\hline FHBP-conjugated PEGDA & $4 \mathrm{~T} 1, \mathrm{MCF}-7$ & Enriched $\mathrm{CD} 44^{\mathrm{hi}} / \mathrm{CD} 24^{\mathrm{lo}}$ subpopulation of breast cancer cells & [72] \\
\hline CD44BP-conjugated PEGDA & $4 \mathrm{~T} 1, \mathrm{MCF}-7$ & Decreased CD $44^{\mathrm{hi}} / \mathrm{CD} 24^{\mathrm{lo}}$ subpopulation of breast cancer cells & [72] \\
\hline \multicolumn{4}{|l|}{ Fully synthetic polymer hydrogels } \\
\hline PMEDSAH & hESC (BG01, H9) & $\begin{array}{l}\text { Pluripotency maintained for over } 20 \text { passages, up to } \\
10 \text { passages in defined media }\end{array}$ & [73] \\
\hline APMAAm & hESC (H1s, H9-hOct4-pGZs) & Sustained culture for over 20 passages in defined media & [74] \\
\hline PMVE-alt-MA & hESC (HUES1, HUES9), iPSC & $\begin{array}{l}\text { Increased endogenous ECM production, maintained } \\
\text { pluripotency for five passages }\end{array}$ & [75] \\
\hline
\end{tabular}

The strategies outlined in the table have been used to create microenvironments, which expand stem cell populations while preserving their phenotype. Comparing the strategies of culturing different types of stem cells reveals common elements, indicating that advances in culturing one type of stem cell may have implications in other stem cell fields as well. However, it should be noted that the use of different growth factors, medias, or culture techniques may contribute to some of the observed results. However, the purpose of this table is to highlight the different substrates and the similarity between different stem cell types, used in culturing of a variety of stem cells.

$M E F$ mouse embryonic fibroblast, ICM inner cell mass, $h E S C$ human embryonic stem cell, iPSC induced pluripotent stem cell, UC umbilical cord, $H S P C$ hematopoietic stem progenitor cell, PMVEC porcine microvascular endothelial cell, $F S$ fetal skin, $F M$ fetal muscle, $h M S C$ human mesenchymal stem cell, $B M$ bone marrow, $L T C$-IC long-term culture initiating cells, $C A F$ cancer-associated fibroblast, CSC cancer stem cell, TCPS tissue culture polystyrene, $P E T$ polyethylene terephthalate, $G F$ growth factor, $M M P$ matrix metalloprotease, $E C M$ extracellular matrix, $P D M S$ polydimethylsiloxane, UVPS ultraviolet-ozone-treated polystyrene, $B S A$ bovine serum albumin, $F B S$ fetal bovine serum, $P C L$ polycaprolactone, $B S P$ bone sialoprotein-derived peptide, $V N$ vitronectin-derived peptide, $s F N$ short fibronectin-binding peptide, $l F N$ long fibronectin-binding peptide, $L M$ laminin-derived peptide, $P A S$ peptide-acrylate surface, $O P N$ osteopontin, $F N$ fibronectin, $S A M$ self-assembled monolayer, $p D A$ polydopamine, $P S$ polystyrene, $P E G$ polyethylene glycol, $F H B P$ fibronectinheparan-binding peptide, $C D 44 B P$ CD44-binding peptide, $P E G D A$ polyethylene glycol diacrylate, $P M V E$-alt- $M A$ poly(methyl vinyl ether-alt-maleic anhydride), APMAAm aminopropylmethacrylamide hydrogel, PMEDSAH poly[2-(methacryloyloxy)ethyl dimethyl-(3sulfopropyl)ammonium hydroxide] 


\section{Feeder Free Culture Using Purified Extracellular Matrix Proteins}

While the expansion of stem cells on human [42, 43] and xenogenic feeder layers has shown success in maintaining pluripotent stem cells for prolonged culture times and multiplying adult human HSCs for therapeutic use, these systems lack control over which signals stem cells are exposed to. Deconstruction of the stem cell niche has led to ECM-based microenvironments that provide an adhesive substrate that interacts directly with cells through integrin signaling, which is suspected to contribute to stem cell maintenance. However, the biological activity of the ECM is more complex than a simple adhesive substrate, as it provides a reservoir for growth factors which can alter their release or presentation, contains cryptic signaling domains, modulates the mechanical stiffness of a substrate, and can be remodeled by cells based on environmental cues. A major advance in the development of more defined microenvironments using ECM coatings came with the first "feeder-free" hESC culture system [18]. This study demonstrated that feeder layers could be eliminated through use of various matrix proteins, either a product of EngelbrethHolm-Swarm mouse sarcoma cells (Matrigel) or purified matrix proteins laminin, collagen IV, or fibronectin coated on tissue-culture plastic in conditioned medium supplemented by human basic fibroblast growth factor (hbFGF).

While the feeder-free systems were able to successfully eliminate the complexity and inconsistency associated with feeder cells, the reliance on MEF conditioned medium remained a source of xenogeneic contamination and unknown composition. Nevertheless, the concept of coating tissueculture plastic with matrix proteins and utilizing conditioned medium both continue to be a popular technique for stem cell culture, including both pluripotent stem cells and adult stem cells. Development and validation of the first defined hESC media, TeSR1, on a substrate coated with purified human matrix proteins marked a significant progression toward the ultimate goal of obtaining a fully defined microenvironment that preserves the pluripotency of hESCs and hiPSCs [49]. Initial work with TeSR 1 demonstrated that hESCs could be grown on a matrix coating consisting of collagen IV, fibronectin, laminin, and vitronectin, an ECM combination that was determined through a screening process. Further studies have demonstrated the ability to maintain pluripotent stem cells on substrates coated with purified fibronectin [50], laminin [52, 53], or vitronectin $[21,56]$. Although these ECM-coated surfaces can maintain hESC and iPSC stem cells, not all surfaces coated with these purified ECM components are successful in maintaining the pluripotent stem cell phenotype [21, 54]. This could be explained in part by the conformational changes of ECM proteins on the coated substrates, which have been demonstrated to depend significantly on the underlying substrate and been shown to impact integrin-binding interactions
[77-81]. Therefore, proteins adsorbed onto different surfaces could express differences in its ability to support pluripotent stem cell culture [56]. Specifically, in the case of pluripotent stem cells, different conformations of Matrigel coated on glass, polystyrene, or tissue culture surfaces have been shown to drastically alter ESC proliferation and differentiation [82]. Similarly, conformational change in osteopontin (Osp) by thrombin-cleavage (tc) results in an inhibitory effect on proliferation and differentiation of human HSCs (CD34 + CD38cells) compared to native Osp-coated surfaces, which induce apoptosis in these cells [83]. Interestingly, the effect of tc-Osp is lost in committed hematopoietic progenitor cells (CD34+ $\mathrm{CD} 38+$ ).

The reason for the success of these substrates is not clearly understood. However, speculation over integrin binding with matrix molecules $[21,55]$ and several cell-signaling pathways are suggested to play a role in stem cells retaining their pluripotency. Nevertheless, limited success of culturing pluripotent stem cells on collagen substrates [84], which contain integrin-binding domains complementary to receptors found on the surfaces of hESCs, leads to questions as to what specific interactions are necessary to preserve the cell's ability to self-renew. One interaction to note that is found in hESCs and hiPSCs is integrin $\alpha 6 \beta 1$, which binds to different subtypes of the laminin family of ECM proteins [17], and recently has been associated with maintaining stemness of pluripotent stem cells and other stem cells. Furthermore, it has recently been shown that integrin $\alpha 6$ can be used as a marker to identify long-term repopulating human hematopoietic stem cells from other multipotent progenitors within a cord blood sample [85]. Integrin $\alpha 6$ has also been implicated as an important regulator of glioblastoma cancer stem cell self-renewal, proliferation, and tumor formation capacity [17]. This has led to recent successes of laminin-coated culture substrates in maintaining the cancer stem cell (CSC) phenotype [61]. Primary brain tumor cells cultured on laminin coated tissue culture flasks led to the isolation of multiple glioma neural stem cell lines, a significant achievement in the field of cancer stem cells. Laminin has also been identified as an important ingredient in the expansion of CSCs from other tissue types as well, including breast cancer where laminin 511 has been linked to enhanced CSC adhesion and growth [64•]. With the demonstrated similarities between the transcriptional factors and signaling pathways associated with hESCs and cancer stem cells [86], it is not surprising that similar culture methods for maintaining these stem cells have been achieved. These results indicate that ECM coatings have some ability to mimic the stem cell niche, without the integration of stromal cells.

The importance of the elimination of the feeder cells, in terms of contributing to basic understanding of stem cell pluripotency, cannot be overstated simply due to the reduction of variables within the culture system. Despite the successful elimination of the unknowns contributed by the feeder cells, 
conditioned media, and xenogenic materials through the use of matrix coated substrates, the inherent complexity of these systems continues to mask the mechanism of how these systems work. This has led to the development of newer surfaces through peptide modified hydrogel substrates which can be utilized to examine specific details and interactions between cells and their microenvironment.

\section{Peptide-Conjugated Polymer Substrates}

It has been demonstrated that proteins bind to cells through specific oligopeptides, often consisting of only a few amino acid units. This concept was first demonstrated with the discovery that the peptide sequence RGD is responsible for cell attachment to the extracellular matrix protein fibronectin [87]. Since then, additional peptide sequences have been discovered within other ECM proteins, such as laminin and collagen, and include KQAGDV, YGYGDALR, FYFDLR, KRLDGS, and LDV [81]. These binding motifs have been found to associate with different integrins on the cell surface, making these peptide sequences a potentially powerful tool to study how integrin binding affects the fundamental stem cell characteristics of self-renewal and differentiation. However, studies using peptide sequences for binding have found that the conformation can drastically alter how the peptides interact with their corresponding integrin [88]. These types of conformational changes that alter cell binding to peptides may also explain some of the discrepancies seen in the protein coatings on the substrates. This concept has been demonstrated in pluripotent stem cell culture through the attachment of a cyclicRGD peptide to an amine-modified tissue culture plate [68]. Coupling of an NHS-PEG-maleimide linker to the surface allowed for the immobilization of cyclic-RGD through a Michael addition reaction. As result, it was shown that the cyclic-RGD surfaces were capable of expanding pluripotent stem cells, while the non-cyclic form of the RGD was not.

Attaching adhesion peptide sequences to other types of substrates has also been explored. Modification of bioinert substrates, such as polyethylene glycol (PEG), with adhesion peptides has been proposed as a method for modifying culture surfaces to create tunable tissue engineering substrates [89]. Attachment of adhesion peptides to bulk hydrogels, or to selfassembled monolayers, provided a new method for creating bioinspired synthetic substrates for pluripotent stem cell expansion. The first example of these types of substrates were acrylate gels modified with peptide sequences from either fibronectin, vitronectin, bone sialoprotein (BSP), or laminin, and were studied in parallel to determine which surface was superior in pluripotent stem cell maintenance [66]. Interestingly, each of the peptide sequences studied contained an RGD sequence motif; however, only the BSP and vitronectin modified acrylate gels were capable of sustaining the stem cell self-renewal, providing further evidence for the importance of the adhering peptide conformation. This study led to the first commercialized biosynthetic substrate, Synthemax ${ }^{\mathrm{TM}}$, which promotes the sustained self-renewal and proliferation of human pluripotent stem cells. Other peptide-conjugated substrates have also been reported, including those which do not contain the well-documented RGD sequence [67]. A notable example is the heparin-binding peptide GKKQRFRHRNRKG, which when bound to the surface using self-assembled monolayers (SAMs), was able to maintain the pluripotency of multiple hES and iPS cell lines for 13 months. This peptide is thought to interact with the glycosaminoglycans on the surface of the cells, facilitating adhesion to the substrate and aiding in the maintenance of the stem cell phenotype. The peptide conjugated onto the surface was found to have superior performance compared to surfaces with integrin-binding RGD sequences by instead interacting with the glycosaminoglycans on the cell surface. Performance of these surfaces could be further enhanced through copresentation of RGD containing peptides and the glycosaminoglycan binding regime, suggesting that both adhesion and integrin interactions contribute to the success of this type of surface modification. Therefore, while integrin interactions play an important role in pluripotent stem cell maintenance, there may be other signaling pathways involved. Peptideconjugated polymers in defined conditions allow for studying these alternative interactions, demonstrating the power of this technique.

Current trends in stem cell culture have expanded the use of biofunctional hydrogels into 3D culture matrices, with the goal to mimic functional aspects of the extracellular matrix. A 3D polyethylene glycol diacrylate hydrogel conjugated with the heparin-binding peptide WQPPRARI, similar to the SAM surface that was able to expand pluripotent stem cells, was utilized for the proliferation of CD44+/CD24- breast cancer stem cells in vitro [72]. Other peptides, such as an integrin-binding peptide or CD44 binding peptide, conjugated to the PEGDA hydrogel led to decreased CD44 expression, indicating a reduction in the CSC population. Similar peptide conjugation strategies that utilize integrin-binding peptides, such as RGD, have also been implemented in 3D hydrogels for culturing HSCs [71]. However, these studies often demonstrate little efficacy in expanding stem cell populations. Current research in tuning the hydrogel mechanics without altering the ligand density [90], as well as creating enzymatically degradable hydrogels, is leading the way toward fabricating synthetic ECM mimics which can study specific interactions of cells and their environment [91]. Peptideconjugated hydrogels therefore provide the ability to probe whether specific cellular interactions are required or sufficient to promote stem cell self-renewal and expansion, making them a unique tool to study specific interactions in the stem cell microenvironment. 


\section{Fully Synthetic Polymer Substrates}

While bioinspired culture platforms provided a means for examining how specific interactions affect stem cell culture, the surfaces are costly and have limited shelf-life. Therefore, the development of a fully synthetic surface for pluripotent stem cell culture could result in affordable culture surfaces for scaled up cell expansion of stem cells in an environment never exposed to undefined biological components $[6,73]$. This could lead to widespread use and implementation resulting in consistent and comparable results, unlike the ECM-coated surfaces that have shown conflicting reports due to batch-tobatch inconsistency. The first fully synthetic surface for pluripotent stem cell culture, which contains no biological moieties, was a zwitterionic hydrogel, with negatively charged sulfate groups and positively charged ammonium groups, called PMEDSAH, short for poly[2-(methacryloyloxy)ethyl dimethyl-(3-sulfopropyl)ammonium hydroxide] [73]. This hydrogel is attached to culture surfaces using surface initiated atom transfer radical polymerization (ATRP) and has been shown to maintain multiple human iPSC [92] and hESC lines[73], for extended number of passages in both chemically defined medium or medium conditioned by human feeder cells. A recent report of iPS cell lines derived on PMEDSAH, and subsequent maintenance of their pluripotency for over 9 months of continuous culture, demonstrates that this platform is a cost-effective and consistent alternative to recombinant protein coatings for the derivation and long-term culture of hiPSCs [93•]. The mechanism for how these surfaces work is not yet fully understood. However, despite the non-fouling nature of the PMEDSAH surfaces, a possible protein interaction on the surface of the zwitterionic hydrogel has been proposed in which the sulfate groups of PMEDSAH act as a mimic of heparan sulfate [84]. The mechanism proposes that the surface would sequester bFGF from the growth media, effectively concentrating it on the surface and protecting it from degradation, thereby enhancing the performance of the surface in maintaining stem cell pluripotency [84]. The role of PMEDSAH in supporting pluripotent stem cells is refined further in recent work investigating how PMEDSAH properties affect pluripotent stem cell growth and maintenance [94•]. The conformational state of the PMEDSAH was demonstrated to play an important role in the growth of pluripotent stem cells. At intermediate hydrogel thicknesses, the hESCs studied show a significantly higher growth rate of undifferentiated colonies when compared to thin or thick coatings of PMEDSAH. It is thought to be due to a combination of different properties including hydrophilicity, surface charge, and the number of interchain interactions of the hydrogel brush.

Since the development of PMEDSAH, there have been other synthetic hydrogel systems developed for culturing pluripotent stem cells. A poly(aminopropylmethacrylamide) surface has been used to maintain cell pluripotency in the defined medium, mTESR-1 [74]. Analysis of its surface dynamics suggests that adsorption of bovine serum albumin (BSA) from the culture media plays a role in the attachment of hESCs on the culture surface. Advancement of high throughput microarray screening platforms has led to the development of additional synthetic hydrogel substrates capable of supporting pluripotent stem cell self-renewal and pluripotency [75]. Screening of polymer arrays for cell adhesion, proliferation, and differentiation potential capabilities determined that 16 polymers could sustain short-term maintenance of pluripotent stem cells. However, only the poly(methyl vinyl ether-alt-maleic anhydride) polymer was capable of supporting pluripotent stem cell growth over five passages [75].

Despite the successes of synthetic culture surfaces in maintaining pluripotent stem cells, reports of culturing other difficult to culture stem cells, such as cancer stem cells or hematopoietic stem cells, on these types of surfaces are scarce in the current literature. A recent study documenting the importance of laminin and integrin interactions demonstrated that the ability of these surfaces is at least partially due to their ability to support cell-secreted laminin [23•, 93•]. With laminin and integrin $\alpha 6$ being crucial components in different types of stem cells, fully synthetic hydrogel surfaces could potentially provide a culture platform for expanding and maintaining stem cells beyond just pluripotent stem cells.

\section{Future Perspectives}

The ability to preserve the phenotype of stem cells in vitro has been a major challenge over the last few decades. This is true for pluripotent stem cells including embryonic stem cells and, more recently, induced pluripotent stem cells, as well as some difficult to culture adult stem cells, such as cancer stem cells and hematopoietic stem cells. Expansion and preservation of these rare stem cells are critical for tissue engineering or regeneration, in vitro drug testing, and treatment of many diseases. While each of these stem cells reside in unique microenvironments in the body, their niche components each consist of extracellular matrix, stromal cells, and soluble signals. This has led to similar in vitro culture strategies for the maintenance of each of these stem cell types. Interestingly, techniques, which have been successful in maintaining pluripotent stem cells, have also been found useful in culturing other types of stem cells. These platforms typically utilize specific elements of the niche to recapitulate specific functions or signals thought to be important in maintaining stem cells. This includes implementation of feeder cells, laminin-coated substrates, and peptide-conjugated hydrogels to engineer microenvironments suitable to human stem cell preservation.

The development of pluripotent stem cell culture platforms has provided great insight into the necessary interactions to preserve the stem cell phenotype and has been instrumental in 
developing techniques useful in culturing other types of stem cells. It has been revealed that there are many similarities between the preservation of pluripotent stem cells and other adult stem cells. One such commonality includes signaling through the laminin binding $\alpha 6$ integrin, which is expressed by stem cells ranging from hematopoietic stem cells, cancer stem cells, and pluripotent stem cells [17, 18, 61, 64•, 85]. This expression has led to many successful culture techniques using laminin-coated surfaces. However, it should be emphasized that the success of these coating technologies relies on maintaining the conformational state of the protein, which has been demonstrated to affect pluripotent stem cells cultured on Matrigel-coated surfaces [82]. Therefore, exploring how ECM conformation affects stem cell maintenance may reveal new strategies for their expansion and preservation. Another consideration to be taken into account is the effect of substrate topography and mechanical properties on stemness, with recent reports demonstrating that both roughness and stiffness affect the self-renewal capabilities of hESCs [95-97]. With this in mind, the creation of a $3 \mathrm{D}$ extracellular matrix microenvironments engineered into natural conformational states could provide a unique culture environment that could be used to study stem cell interactions with specific matrix components.

Implementation of synthetic hydrogels, often in conjunction with conjugated peptides, has also shown promise in expanding a variety of stem cell populations. With laminin being naturally secreted by embryonic stem cells and cancer stem cells, a culture surface that can properly support the secreted laminin could possibly be able to support stem cells in vitro. For example, synthetic culture surfaces, such as PMEDSAH, which do not directly interact with cell signaling receptors but provide a conductive environment for cells to create their own niche [23•], could result in more accurate models of in vivo stem cell niches. Expanding the use of these fully synthetic hydrogel surfaces to other types of stem cells, beyond pluripotent stem cells, will be an important step toward scalable stem cell technologies required for therapeutic uses or in vitro drug testing. In conjunction with the important progress with fully defined media, the work on synthetic substrates will play a critical role in controlling stem cell differentiation and widespread implementation.

Acknowledgments J.H.J. acknowledges the support of NIH's Microfluidics in Biomedical Sciences Training Program: NIH NIBIB T32 EB005582. L.V.D acknowledges the support of NIH grant R01DE016530-08. We would also like to thank Bradley Plummer for his useful insight into pluripotent stem cell culture strategies.

\section{Compliance with Ethics Standards}

Conflict of Interest Jacob H. Jordahl, Luis Villa-Diaz, Paul H. Krebsbach, and Joerg Lahann declare that they have no conflict of interest.
Human and Animal Rights and Informed Consent This article does not contain any studies with human or animal subjects performed by any of the authors.

\section{References}

Papers of particular interest, published recently, have been highlighted as:

- Of importance

1. Altering bacteriological plastic petri dishes for tissue culture use Public health reports. 1966;81:843-4.

2. Amstein CF, Hartman PA. Adaptation of plastic surfaces for tissue culture by glow discharge. J Clin Microbiol. 1975;2:46-54.

3. Maroudas NG. Adhesion and spreading of cells on charged surfaces. J Theor Biol. 1975;49:417-24.

4. Maroudas NG. Sulphonated polystyrene as an optimal substratum for the adhesion and spreading of mesenchymal cells in monovalent and divalent saline solutions. J Cell Physiol. 1977;90:511-9.

5. Reubinoff BE, Pera MF, Fong CY, et al. Embryonic stem cell lines from human blastocysts: somatic differentiation in vitro. Nat Biotechnol. 2000;18:399-404.

6. Villa-Diaz LG, Ross AM, Lahann J, et al. Concise review: the evolution of human pluripotent stem cell culture: from feeder cells to synthetic coatings. Stem Cells. 2013;31:1-7.

7. Thomson JA, Itskovitz-Eldor J, Shapiro SS, et al. Embryonic stem cell lines derived from human blastocysts. Science. 1998;282: $1145-7$.

8. Adams GB, Scadden DT. The hematopoietic stem cell in its place. Nat Immunol. 2006; 7:333-7.

9. Doetsch F. A niche for adult neural stem cells. Curr Opin Genet Dev. 2003;13:543-50.

10. Blanpain C, Fuchs E. Epidermal stem cells of the skin. Annu Rev Cell Dev Biol. 2006;22:339-73.

11. Chen Z, de Paiva CS, Luo L, et al. Characterization of putative stem cell phenotype in human limbal epithelia. Stem Cells. 2004;22: 355-66.

12. Fujimoto K, Beauchamp RD, Whitehead RH. Identification and isolation of candidate human colonic clonogenic cells based on cell surface integrin expression. Gastroenterology. 2002;123:1941-8.

13. Jones PH, Watt FM. Separation of human epidermal stem cells from transit amplifying cells on the basis of differences in integrin function and expression. Cell. 1993;73:713-24.

14. Suzuki A, Zheng Y, Kondo R, et al. Flow-cytometric separation and enrichment of hepatic progenitor cells in the developing mouse liver. Hepatology. 2000;32:1230-9.

15. Shinohara T, Avarbock MR, Brinster RL. beta1- and alpha6integrin are surface markers on mouse spermatogonial stem cells. Proc Natl Acad Sci U S A. 1999;96:5504-9.

16. Lathia JD, Patton B, Eckley DM, et al. Patterns of laminins and integrins in the embryonic ventricular zone of the CNS. J Comp Neurol. 2007;505:630-43.

17. Lathia JD, Gallagher J, Heddleston JM, et al. Integrin alpha 6 regulates glioblastoma stem cells. Cell Stem Cell. 2010;6:421-32.

18. $\mathrm{Xu} \mathrm{CH}$, Inokuma MS, Denham J, et al. Feeder-free growth of undifferentiated human embryonic stem cells. Nat Biotechnol. 2001;19:971-4.

19. Leivo I, Vaheri A, Timpl R, et al. Appearance and distribution of collagens and laminin in the early mouse embryo. Dev Biol. 1980;76:100-14. 
20. Miyazaki T, Futaki S, Hasegawa K, et al. Recombinant human laminin isoforms can support the undifferentiated growth of human embryonic stem cells. Biochem Biophys Res Commun. 2008;375: 27-32.

21. Braam SR, Zeinstra L, Litjens S, et al. Recombinant vitronectin is a functionally defined substrate that supports human embryonic stem cell self-renewal via alpha V beta 5 integrin. Stem Cells. 2008;26: 2257-65.

22. Lu J, Hou R, Booth CJ, et al. Defined culture conditions of human embryonic stem cells. Proc Natl Acad Sci U S A. 2006;103:568893.

23. Laperle A, Hsiao C, Lampe M, et al. Alpha-5 laminin synthesized by human pluripotent stem cells promotes self-renewal. Stem Cell Reports. 2015;5:195-206. These authors examined how endogenously secreted ECM proteins interact with defined synthetic substrates, and how that affects pluripotent stem cell culture. It was also shown that some activity of endogenous ECM can be replaced with exogenous sources.

24. Martin GR, Evans MJ. Differentiation of clonal lines of teratocarcinoma cells - formation of embryoid bodies in vitro. P Natl Acad Sci USA. 1975;72:1441-5.

25. Evans MJ, Kaufman MH. Establishment in culture of pluripotential cells from mouse embryos. Nature. 1981;292:154-6.

26. Martin GR. Isolation of a pluripotent cell-line from early mouse embryos cultured in medium Conditioned by Teratocarcinoma Stem-Cells. P Natl Acad Sci-Biol. 1981;78:7634-8.

27. Bongso A, Fong $\mathrm{CY}, \mathrm{Ng} \mathrm{SC}$, et al. Isolation and culture of inner cell mass cells from human blastocysts. Hum Reprod. 1994;9:2110-7.

28. Amit M, Carpenter MK, Inokuma MS, et al. Clonally derived human embryonic stem cell lines maintain pluripotency and proliferative potential for prolonged periods of culture. Dev Biol. 2000;227:271-8.

29. Takahashi K, Tanabe K, Ohnuki M, et al. Induction of pluripotent stem cells from adult human fibroblasts by defined factors. Cell. 2007;131:861-72.

30. Copelan EA. Medical progress: hematopoietic stem-cell transplantation. New Engl J Med. 2006;354:1813-26.

31. Majumdar MK, Thiede MA, Haynesworth SE, et al. Human marrow-derived mesenchymal stem cells (MSCs) express hematopoietic cytokines and support long-term hematopoiesis when differentiated toward stromal and osteogenic lineages. J Hematother Stem Cell Res. 2000;9:841-8.

32. Flores-Guzman P, Fernandez-Sanchez V, Mayani H. Concise review: ex vivo expansion of cord blood-derived hematopoietic stem and progenitor cells: basic principles, experimental approaches, and impact in regenerative medicine. Stem Cells Transl Med. 2013;2: $830-8$.

33. Xu MJ, Tsuji K, Ueda T, et al. Stimulation of mouse and human primitive hematopoiesis by murine embryonic aorta-gonadmesonephros-derived stromal cell lines. Blood. 1998;92:2032-40.

34. Wilson A, Trumpp A. Bone-marrow haematopoietic-stem-cell niches. Nat Rev Immunol. 2006;6:93-106.

35. Nagasawa T, Omatsu Y, Sugiyama T. Control of hematopoietic stem cells by the bone marrow stromal niche: the role of reticular cells. Trends Immunol. 2011;32:315-20.

36. Taichman RS, Emerson SG. Human osteoblasts support hematopoiesis through the production of granulocyte-colony-stimulating factor. J Exp Med. 1994;179:1677-82.

37. McNiece I, Harrington J, Turney J, et al. Ex vivo expansion of cord blood mononuclear cells on mesenchymal stem cells. Cytotherapy. 2004;6:311-7.

38. Kadereit S, Deeds LS, Haynesworth SE, et al. Expansion of LTCICs and maintenance of $\mathrm{p} 21$ and BCL-2 expression in cord blood CD34(+)/CD38(-) early progenitors cultured over human MSCs as a feeder layer. Stem Cells. 2002;20:573-82.
39. Zhang Y, Li CD, Jiang XX, et al. Human placenta-derived mesenchymal progenitor cells support culture expansion of long-term culture-initiating cells from cord blood CD34(+) cells. Exp Hematol. 2004;32:657-64.

40. Rosler E, Brandt J, Chute J, et al. Cocultivation of umbilical cord blood cells with endothelial cells leads to extensive amplification of competent CD34(+)CD38(-) cells. Exp Hematol. 2000;28:841-52.

41. Nolta JA, Thiemann FT, Arakawa-Hoyt J, et al. The AFT024 stromal cell line supports long-term ex vivo maintenance of engrafting multipotent human hematopoietic progenitors. Leukemia. 2002;16: 352-61.

42. Richards M, Fong CY, Chan WK, et al. Human feeders support prolonged undifferentiated growth of human inner cell masses and embryonic stem cells. Nat Biotechnol. 2002;20:933-6.

43. Hovatta O, Mikkola M, Gertow K, et al. A culture system using human foreskin fibroblasts as feeder cells allows production of human embryonic stem cells. Hum Reprod. 2003;18:1404-9.

44. Wang JF, Wang LJ, Wu YF, et al. Mesenchymal stem/progenitor cells in human umbilical cord blood as support for ex vivo expansion of CD34(+) hematopoietic stem cells and for chondrogenic differentiation. Haematologica. 2004;89:837-44.

45. Teixidó J, Hemler ME, Greenberger JS, et al. Role of beta 1 and beta 2 integrins in the adhesion of human CD34hi stem cells to bone marrow stroma. J Clin Investig. 1992;90:358-67.

46. Giannoni E, Bianchini F, Masieri L, et al. Reciprocal activation of prostate cancer cells and cancer-associated fibroblasts stimulates epithelial-mesenchymal transition and cancer stemness. Cancer Res. 2010;70:6945-56.

47. Vermeulen L, De Sousa E Melo F, van der Heijden M, et al. Wnt activity defines colon cancer stem cells and is regulated by the microenvironment. Nat Cell Biol. 2010;12:468-76.

48. Liu S, Ginestier C, Ou SJ, et al. Breast cancer stem cells are regulated by mesenchymal stem cells through cytokine networks. Cancer Res. 2011;71:614-24.

49. Ludwig TE, Levenstein ME, Jones JM, et al. Derivation of human embryonic stem cells in defined conditions. Nat Biotechnol. 2006;24:185-7.

50. Amit M, Shariki C, Margulets V, et al. Feeder layer- and serum-free culture of human embryonic stem cells. Biol Reprod. 2004;70:83745.

51. Li Z, Leung M, Hopper R, et al. Feeder-free self-renewal of human embryonic stem cells in 3D porous natural polymer scaffolds. Biomaterials. 2010;31:404-12.

52. Rodin S, Domogatskaya A, Strom S, et al. Long-term self-renewal of human pluripotent stem cells on human recombinant laminin511. Nat Biotech. 2010;28:611-5.

53. Rodin $\mathrm{S}$, Antonsson L, Niaudet $\mathrm{C}$, et al. Clonal culturing of human embryonic stem cells on laminin-521/E-cadherin matrix in defined and xeno-free environment. Nat Commun. 2014;5:3195.

54. Hakala H, Rajala K, Ojala M, et al. Comparison of biomaterials and extracellular matrices as a culture platform for multiple, independently derived human embryonic stem cell lines. Tissue Eng A. 2009; 15:1775-85.

55. Rowland TJ, Miller LM, Blaschke AJ, et al. Roles of integrins in human induced pluripotent stem cell growth on Matrigel and vitronectin. Stem Cells Dev. 2010;19:1231-40.

56. Saha K, Mei Y, Reisterer CM, et al. Surface-engineered substrates for improved human pluripotent stem cell culture under fully defined conditions. Proc Natl Acad Sci U S A. 2011;108:18714-9.

57. Sharma MB, Limaye LS, Kale VP. Mimicking the functional hematopoietic stem cell niche in vitro: recapitulation of marrow physiology by hydrogel-based three-dimensional cultures of mesenchymal stromal cells. Haematologica. 2012;97:651-60.

58. Ferreira MS, Jahnen-Dechent W, Labude N, et al. Cord bloodhematopoietic stem cell expansion in 3D fibrin scaffolds with stromal support. Biomaterials. 2012;33:6987-97. 
59. Feng Q, Chai C, Jiang XS, et al. Expansion of engrafting human hematopoietic stem/progenitor cells in three-dimensional scaffolds with surface-immobilized fibronectin. J Biom Mat Res Part A. 2006;78:781-91.

60. Liu J, Tan Y, Zhang H, et al. Soft fibrin gels promote selection and growth of tumorigenic cells. Nat Mater. 2012;11:734-41.

61. Pollard SM, Yoshikawa K, Clarke ID, et al. Glioma stem cell lines expanded in adherent culture have tumor-specific phenotypes and are suitable for chemical and genetic screens. Cell Stem Cell. 2009;4:568-80.

62. Chen L, Xiao Z, Meng Y, et al. The enhancement of cancer stem cell properties of MCF-7 cells in 3D collagen scaffolds for modeling of cancer and anti-cancer drugs. Biomaterials. 2012;33:143744.

63. Zhang W, Choi DS, Nguyen YH, et al. Studying cancer stem cell dynamics on PDMS surfaces for microfluidics device design. Sci Rep. 2013;3:2332.

64. Chang C, Goel HL, Gao H, et al. A laminin 511 matrix is regulated by TAZ and functions as the ligand for the alpha6Bbeta1 integrin to sustain breast cancer stem cells. Genes Dev. 2015;29:1-6. One of the first papers that highlighted the importance of ECM proteins in 2D breast cancer stem cell culture. This study shows that laminin-511 and its interaction with integrin $\alpha 6$ is critical for maintaining cancer stem cells. It also demonstrates that laminin-511 binding activates TAZ, and TAZ activation regulates the expression of laminin-511, indicating laminin-511 is a critical niche component for breast cancer stem cells.

65. Feng S, Duan X, Lo PK, et al. Expansion of breast cancer stem cells with fibrous scaffolds. Integr Biol: Quant Biosci Nano Macro. 2013;5:768-77.

66. Melkoumian Z, Weber JL, Weber DM, et al. Synthetic peptideacrylate surfaces for long-term self-renewal and cardiomyocyte differentiation of human embryonic stem cells. Nat Biotechnol. 2010;28:606-U95.

67. Klim JR, Li LY, Wrighton PJ, et al. A defined glycosaminoglycanbinding substratum for human pluripotent stem cells. Nat Methods. 2010;7:989-U72.

68. Kolhar P, Kotamraju VR, Hikita ST, et al. Synthetic surfaces for human embryonic stem cell culture. J Biotechnol. 2010;146:143-6.

69. Park HJ, Yang K, Kim MJ, et al. Bio-inspired oligovitronectingrafted surface for enhanced self-renewal and long-term maintenance of human pluripotent stem cells under feeder-free conditions. Biomaterials. 2015;50:127-39.

70. Muth CA, Steinl C, Klein G, et al. Regulation of hematopoietic stem cell behavior by the nanostructured presentation of extracellular matrix components. PLoS One. 2013;8:e54778.

71. Raic A, Rodling L, Kalbacher H, et al. Biomimetic macroporous PEG hydrogels as 3D scaffolds for the multiplication of human hematopoietic stem and progenitor cells. Biomaterials. 2014;35: 929-40.

72. Yang X, Sarvestani SK, Moeinzadeh S, et al. Effect of CD44 binding peptide conjugated to an engineered inert matrix on maintenance of breast cancer stem cells and tumorsphere formation. PLoS One. 2013;8:e59147.

73. Villa-Diaz LG, Nandivada H, Ding J, et al. Synthetic polymer coatings for long-term growth of human embryonic stem cells. Nat Biotechnol. 2010;28:581-3.

74. Irwin EE, Gupta R, Dashti DC, et al. Engineered polymer-media interfaces for the long-term self-renewal of human embryonic stem cells. Biomaterials. 2011;32:6912-9.

75. Brafman DA, Chang CW, Fernandez A, et al. Long-term human pluripotent stem cell self-renewal on synthetic polymer surfaces. Biomaterials. 2010;31:9135-44.

76. de Lima M, McNiece I, Robinson SN, et al. Cord-blood engraftment with ex vivo mesenchymal-cell coculture. New Engl J Med. 2012;367:2305-15.
77. Michael KE, Vernekar VN, Keselowsky BG, et al. Adsorptioninduced conformational changes in fibronectin due to interactions with well-defined surface chemistries. Langmuir. 2003;19:803340 .

78. Katz BZ, Zamir E, Bershadsky A, et al. Physical state of the extracellular matrix regulates the structure and molecular composition of cell-matrix adhesions. Mol Biol Cell. 2000;11:1047-60.

79. Garcia AJ, Vega MD, Boettiger D. Modulation of cell proliferation and differentiation through substrate-dependent changes in fibronectin conformation. Mol Biol Cell. 1999;10:785-98.

80. Hernandez JCR, Sanchez MS, Soria JM, et al. Substrate chemistrydependent conformations of single laminin molecules on polymer surfaces are revealed by the phase signal of atomic force microscopy. Biophys J. 2007;93:202-7.

81. Ruoslahti E. RGD and other recognition sequences for integrins. Annu Rev Cell Dev Bi. 1996;12:697-715.

82. Kohen NT, Little LE, Healy KE. Characterization of Matrigel interfaces during defined human embryonic stem cell culture. Biointerphases. 2009;4:69-79.

83. Nilsson SK, Johnston HM, Whitty GA, et al. Osteopontin, a key component of the hematopoietic stem cell niche and regulator of primitive hematopoietic progenitor cells. Blood. 2005;106:1232-9.

84. Lambshead JW, Meagher L, O'Brien C, et al. Defining synthetic surfaces for human pluripotent stem cell culture. Cell Regen (Lond). 2013;2:7.

85. Notta F, Doulatov S, Laurenti E, et al. Isolation of single human hematopoietic stem cells capable of long-term multilineage engraftment. Science. 2011;333:218-21.

86. Ben-Porath I, Thomson MW, Carey VJ, et al. An embryonic stem cell-like gene expression signature in poorly differentiated aggressive human tumors. Nat Genet. 2008;40:499-507.

87. Pierschbacher MD, Ruoslahti E. Cell attachment activity of fibronectin can be duplicated by small synthetic fragments of the molecule. Nature. 1984;309:30-3.

88. Pfaff M, Tangemann K, Muller B, et al. Selective recognition of cyclic RGD peptides of NMR defined conformation by alpha IIb beta 3 , alpha $\mathrm{V}$ beta 3 , and alpha 5 beta 1 integrins. J Biol Chem. 1994;269:20233-8.

89. Hern DL, Hubbell JA. Incorporation of adhesion peptides into nonadhesive hydrogels useful for tissue resurfacing. J Biomed Mater Res. 1998;39:266-76.

90. Schweller RM, West JL. Encoding hydrogel mechanics via network cross-linking structure. ACS Biomaterials Sci Eng. 2015;1:335-44.

91. Tibbitt MW, Anseth KS. Hydrogels as extracellular matrix mimics for 3D cell culture. Biotechnol Bioeng. 2009;103:655-63.

92. Villa-Diaz LG, Brown SE, Liu Y, et al. Derivation of mesenchymal stem cells from human induced pluripotent stem cells cultured on synthetic substrates. Stem Cells. 2012;30:1174-81.

93. Villa-Diaz LG, Kim JK, Lahann I, et al. Derivation and Long-Term Culture of Transgene-Free Human Induced Pluripotent Stem Cells on Synthetic Substrates. Stem cells translational medicine. 2014;3: 1410-7. This work demonstrated for the first time that human iPSCs can be derived and cultured for long periods of time on synthetic polymer coatings in a xeno-free medium, nearing clinically relevant conditions.

94. Qian X, Villa-Diaz LG, Kumar R, et al. Enhancement of the propagation of human embryonic stem cells by modifications in the gel architecture of PMEDSAH polymer coatings. Biomaterials. 2014;35:9581-90. This work showed how modifcations in the gel architecture of the polymers can impact the biology of stem cells, in this case by promoting large scale expansion of hESCs.

95. Chen W, Villa-Diaz LG, Sun Y, et al. Nanotopography influences adhesion, spreading, and self-renewal of human embryonic stem cells. ACS Nano. 2012;6:4094-103. 
96. Sun Y, Villa-Diaz LG, Lam RH, et al. Mechanics regulates fate decisions of human embryonic stem cells. PLoS One. 2012;7: e37178.
97. Sun Y, Yong KM, Villa-Diaz LG, et al. Hippo/YAP-mediated rigidity-dependent motor neuron differentiation of human pluripotent stem cells. Nat Mater. 2014;13:599-604. 